\title{
1 \\ Prototypes, polysemy and constructional semantics: The lexicogrammar of the English verb climb
}

Cliff Goddard

\section{Anna Wierzbicka on prototypes, polysemy and constructional semantics}

Three themes in the work of Anna Wierzbicka inform the present study and the predecessor work upon which it rests. The first is her long-term engagement with prototypes in semantics. Rejecting the conventional dichotomy between prototypes and semantic invariants, she has long insisted that a prototype can be 'part of the semantic invariant itself' (Wierzbicka 1996: 167).

Second, Wierzbicka has always recognised that lexical polysemy is normal, indeed ubiquitous, in everyday language and that it is impossible to reach valid generalisations about words, meaning and grammar without taking polysemy seriously. This means not only adopting a rigorous methodology whereby one can reliably distinguish genuine polysemy from generality or vagueness of meaning, but being prepared to put in weeks or months of painstaking effort to disentangle complex polysemic networks of intertwined lexical, phraseological and grammatical meanings. 
Third, far from being narrowly focused on lexical meaning, Wierzbicka was one of the pioneers of what is now discussed under rubrics such as constructional semantics and lexicogrammar. In her seminal 1982 article 'Why can you have a drink when you can't *have an eat?' in the journal Language, she proposed a set of interrelated semantic schemas for 'have a VP [verb phrase]' constructions. Although the slots in these schemas were filled by items from specific semantic-lexical subclasses, each schema as a whole expressed a larger meaning that was not a simple compositional function of its individual parts.

Thirty years ago, in The Semantics of Grammar (1988), she wrote:

There is no such thing as 'grammatical meaning' or 'lexical meaning'. There are only grammatical and lexical MEANS of conveying meaning - and even here no sharp line can be drawn between them. (Wierzbicka 1988: 8)

Underpinning Wierzbicka's decades of semantic description and theoretical innovation, one goal has remained constant: the 'sustained effort to establish, and verify, the basic stock of human concepts-universal semantic primitives-out of which thoughts and complex concepts are constructed' (1996: 169). Though valuable in themselves, the hundreds of empirical studies conducted in the Natural Semantic Metalanguage (NSM) approach collectively bear on this overarching task. In 2020, NSM researchers believe that this task has essentially been accomplished. ${ }^{1}$

In past decade or so, there has been intensive NSM research on physical activity verbs (Sibly 2010; Ye 2010; Goddard 2012; Goddard and Wierzbicka 2016; Goddard, Wierzbicka and Wong 2016; Goddard 2018: Ch 5). In the present study, I draw on this body of work to explore the semantics and lexicogrammar of a single English verb: climb.

\section{The puzzle of English 'climb'}

Charles Fillmore (1982) influentially used English climb as an example of a verb whose meaning could not be described using a set of necessary and sufficient conditions. According to Fillmore, climb normally or

1 Goddard (2018: Ch 3) gives a brief history of the NSM approach. Though certain aspects of the metalanguage syntax remain to be worked out fully, the last amendment to the inventory of primes itself-replacing HAVE (sOMETHING) with (IS) MINE-was implemented in 2016. 
prototypically signals two semantic components, roughly (i) moving upward, (ii) using a 'clambering' manner, but in extended uses either condition (but not both) can be set aside. For example, a person or a monkey can readily be said to climb down a tree (i.e. without the upwards direction component), while a snail or a snake can be said climb (up) a tree (i.e. without the 'clambering' component). The same snail or snake, however, could not be said to climb down.

This is indeed a striking observation. However, as noted in Wierzbicka (1996) and in earlier works, if moving upwards is merely part of a prototype and not part of the invariant meaning, why can a sentence like The monkey climbed the flagpole not be interpreted as meaning that the monkey climbed down. How can we be so sure that, unless otherwise specified, the direction of movement is upwards? Wierzbicka also noted that there is more to it than just the two components mentioned by Fillmore. For example, an extended use of another kind, in the sentence The train climbed the mountain, implies more than simply upwards direction. Without any qualification to the contrary, this sentence would not be a good description if the train had sped quickly up the mountain.

Over the following years and decades, English climb continued to be revisited by linguists of different persuasions. Ray Jackendoff (1983, 1985, 1990) formalised Fillmore's observations using a 'preference rule system', and in a series of papers Beth Levin and Malka Rappaport Hovav (e.g. Rappaport Hovav and Levin 2010; Levin and Rappaport Hovav 2013) puzzled over climb as they sought to develop a simple schematics for verbs, according to which Manner and Result are (or ought to be) in a complementary relationship; that is, verbs or uses of verbs ought to be Manner-oriented or Result-oriented but not both. Verbs like climb (and cut) seemed to challenge this idea and the debate shows little sign of reaching a conclusion, even after 30 years (cf. e.g. Chen and Husband 2019).

In my view, the reasons for the slow rate of progress come down to problems of method and approach. The lexical semantics of climb (and $c u t$ ) in fact intertwine Manner and Result components. They also interact with grammatical aspect. It is all very semantically complex, very intricate; but conventional approaches are not greatly interested in semantic complexity (= accuracy) for its own sake. Many linguists are concerned first and foremost with formal syntax and so the effort is always to schematise the semantics, to keep the fine semantic details 
to a minimum. In the experience of NSM linguists, it is a false economy and a self-defeating strategy to stave off detailed work on semantics in the hope of reaching the big picture first. Deciding not to focus one's lens is a formula for seeing a fuzzy picture.

I have two further observations about verb semantics in the mainstream 'syntax and semantics' literature. First, there has been remarkably little interest in the details of Manner specifications. For decades there was no progress beyond Fillmore's descriptor 'clambering' (itself a complex and highly English-specific term). Jackendoff (1990) mentioned 'effortful grasping motions' but went straight back to using 'clambering' as an abbreviation. Not until the new century did Geuder and Weisgerber (2006) contribute a new idea, namely, 'force exertion against gravity', and although this formulation can no doubt be improved, it conveys the idea that climbing involves effort, and hints, perhaps, at the possibility of falling.

My second observation concerns the stubborn persistence of the idea that so-called 'syntactic alternations' can be revealingly described with minimal reference to semantics. Already in 2000, David Dowty challenged this view, from within the generative fold, in an article whose title contains the phrase 'the fallacy of argument alternation'. He wrote:

[C] ontrary to the usual view ... good reasons can be given to view it as a lexical derivation analogous to rules of WORD FORMATION on the one hand, and to processes of LeXICAL SEMANTIC EXTENSION $\ldots$ and METAPHOR on the other. (Dowty 2000: 121; emphasis in original)

The 'main linguistic phenomenon that ought to be of interest', Dowty said, is that alternate constructions 'serve to convey significantly different meanings' (2000: 110). To make good on this insight, however, depends on being able to capture meanings and meaning differences in a rigorous and cognitively plausible fashion.

2 Dowty was speaking of the so-called locative-subject construction; for example, The garden is swarming with bees, but his comments were intended to have broader implications. 


\section{Verb semantics, aspect and constructional semantics: The view from 2020}

This is a thumbnail sketch of current NSM work with verb semantics, aspectual transposition and constructional semantics. To explicate verbs, one must first decide on a basic grammatical frame for the verb in question, which will include its core arguments and its inherent aspect. For English physical activity verbs like walk, run, cut, chop and grind, the basic frame is 'activity-in-progress', expressed with the present progressive. To anticipate, for climb we will start with the basic frame: Someone $X$ is climbing something (e.g. a tree, a ladder, garden wall).

Verbs of a given semantic class are expected to follow the same semantic template, sometimes with minor variations. In their basic activity-inprogress meanings, English physical activity verbs have a four-part semantic template. The section headings and some key points about each of them are given in Table 1.1.

Table 1.1. Semantic template for activity-in-progress, with key points.

LEXICOSYNTACTIC FRAME. Very general. Hinged around primes DO, HAPPEN and MOVE. Identifies the main participants and other grammatically salient things such as inherent aspect (e.g. 'for some time' (durational)), and whether the activity is necessarily localised (i.e. done 'in a place').

PROTOTYPICAL SCENARIO. Introduced by 'often when someone does this, it is like this: ...' Includes the intention or mental state of the prototypical actor, which is always a pivotal component. ${ }^{3}$

HOW IT HAPPENS (MANNER). Introduced by 'often when someone does this, it happens like this', plus, if iterative: 'it happens like this many times'.

May include an incremental effect.

potential outcome. Specifies that if done 'for some time', the activity can be effective in bringing about the desired result.

Source: Author's summary.

As for the individual semantic components in NSM explications, they are chiefly written in semantic primes. Explications can also include complex lexical meanings, either as semantic molecules or as derivational bases.

3 The explications in this chapter use 'often' as a portmanteau for 'at many times', as is now standard in recent NSM work. 
Both are relevant to the present study. Semantic molecules, marked as [m], are complex meanings that function as recurring units in the structure of many concepts across many domains (Goddard 2011: 375-84; Goddard and Wierzbicka 2014: Chs 2-4). The explications for climb will require the semantic molecules 'hands $[\mathrm{m}]$ ', 'legs [m]', 'ground [m]', 'at the top [m]' and 'at the bottom [m]'. Derivational bases, marked as [d], are complex lexical meanings that enter into explications in a much more limited and localised fashion; that is, in derivational processes, in quasi-derivational extensions from a basic lexical meaning to a more elaborated one, and in specialised lexicogrammatical constructions (Goddard 2018: 235-64).

The concept of [d] elements was originally developed to deal with 'visible' derivational relationships, e.g. between the words ill and illness, or between the noun knife and the verb to knife (someone). The idea was that the simpler of the two meanings could appear inside the explication of the more complex one; for example, the explication of the noun illness could include 'ill [d]'; the explication for the verb to knife could include 'knife [d]'. As will be shown in the present study, however, the idea of [d] elements has turned out to have far broader applications.

One of these applications is to allow a quasi-derivational treatment of grammatical aspect. This is relevant to the present study because many semantically specialised constructions, including for the verb climb, are found preferentially in perfective contexts; for example, in the English simple past. Briefly, the idea is that verbs like climb and cut can also appear in a perfective (e.g. simple past) template with three sections:

(i) LEXICOSYNTACTIC FRAME: 'someone $\mathrm{X}$ did something (to something) at this time', that is, a temporally localised act without reference to its duration.

(ii) HOW IT HAPPENED (MANNER): described using the activity-inprogress meaning as a [d] element; for example, 'someone ate something' includes 'this someone was eating [d] it for some time'.

(iii) outcome: the achievement of a particular goal envisaged by the actor.

This approach corresponds closely to standard descriptions of the perfective as viewing an event in its totality without attention to its internal temporal constituency (Comrie 1993). 


\section{Extended meanings and uses of English 'climb'}

We begin our exploration of climb not by explicating its semantically basic meaning, but from the other direction, as it were: by showing how various non-basic uses of climb can be accounted for, assuming that we have an explication for 'is climbing' and can use it as a [d] element. Consider the simple past of climb. It is explicated in [A].

\section{[A] She climbed, a tree (tree, ladder, wall) [i.e. simple past]}

she (= this someone) did something in a place at this time LEXICOSYNTACTIC

FRAME

it happened like this:

HOW IT HAPPENED

a short time before, she thought like this about (MANNER) something in this place (a tree, ladder, wall):

'I want to be at the top [m] of this something'

because of this, she was climbing [d] this tree (ladder, wall) for some time

because of this, after this, she was not in the place where she was before

OUTCOME she was at the top [m] of this tree (ladder, wall) as she wanted

Explication [A] involves literal 'climbing [d]', and as we will see when it is explicated (in section 5), 'climbing [d]' includes a semantic component of upwards motion. What about climb down then, or climb onto something?

Climb down is quite a high-frequency expression in the Collins Wordbanks Online corpus (hereafter: Wordbanks). It is explicated in [B]. Although the How It Happened section still uses 'climbing [d]', it is positioned inside in an 'analogy of manner' component: 'he did something for some time like someone does when this someone is climbing [d] something'. 


\section{[B] He climbed ${ }_{2}$ down the tree (ladder, wall)}

he did something in a place at this time

LEXICOSYNTACTIC

FRAME

it happened like this:

HOW IT HAPPENED

a short time before, he thought like this about

(MANNER)

something in this place (a tree, ladder, wall):

'I want to be at the bottom [m] of this something'

because of this, he did something for some time

like someone does when this someone is climbing [d]

something

because of this, after this, he was not in the place

OUTCOME

where he was before

he was at the bottom [m] of this tree (ladder, wall) as he wanted

Now let us consider examples when climb appears with other adverbial modifiers, especially prepositional phrases with into, off, onto, out onto, out from, out from under, etc. Such expressions are extremely common in English, helping to put climb into the 350 most frequent verbs in the English language, and, possibly, into the top 20 physical activity verbs. ${ }^{4}$

(1) a. He climbed into bed, into the passenger seat, etc.

b. She climbed onto the roof of the car.

c. He climbed out of the car (cabin, backseat, etc. $)^{5}$

(2) a. He opened the window and climbed out onto the windowsill.

b. They climbed out from under the table.

4 These statements are based on word frequency figures taken from COCA (Corpus of Contemporary American English): www.wordfrequency.info/free.asp?s=y. 'Climb' appears in rank 334 of verbs. Rather strikingly, however, a manual count shows that physical activity verbs constitute only about $10-15 \%$ of the top 350 . Restricting ourselves only to physical activity verbs, climb comes after the following, given in order of frequency: go, come, play, run, hold, sit, stand, walk, build, cut, carry, eat, fight, laugh, sing, drink, cry, cook.

5 It seems worth noting that climbed out of has a very high frequency in Wordbanks, more than 1,300 instances, nearly three times as many as climbed down. 
c. The 22-year-old New Zealand-born pilot actually climbed out onto the wing of his plane while it was at 13,000 feet ...

d. a one-year-old boy who apparently was looking for his mother climbed out onto a window ledge ...

Explication $[\mathrm{C}]$ is for sentences like He climbed onto the roof of the car or He climbed into bed.

\section{[C] He climbed ${ }_{2}$ onto the roof of the car}

he did something at this time in a place

LEXICOSYNTACTIC

FRAME

it happened like this:

HOW IT HAPPENED

a short time before, he thought like this about

(MANNER)

something in this place (a car):

'I want to be on the roof of this car'

because of this, he did something for some time

like someone does when this someone is climbing [d]

something

because of this, after this, he was not in the place

OUTCOME

where he was before

he was on the roof of the car as he wanted

I will now sketch how other extended uses of English climb can be accounted for in similar fashion, beginning with instances in which non-human creatures are said to climb. In the case of monkeys, who, as already mentioned, can be said to climb down as well as up, explication [B] will be appropriate with only minor adjustments, given that one thinks of monkeys as having similar bodies and mental capacities to humans. For creatures like snails and snakes, on the other hand, a version of the analogy mechanism shown in [C] will be needed. Sentences like the following (garnered from the internet) are not uncommon.

(3) a. Why do snails climb up walls when it rains?

b. Can snakes climb stairs?

c. I was staring at it for a while as it climbed up my shelving before it registered for me that it was a snake. 
In another phraseological cluster, prices, wages, temperatures, sales figures, ratings, population numbers and the like, which all involve numbers (numerical values), can be said to $\operatorname{limb}$, implying that they move steadily upwards. For example:

(4) a. Facebook's stock price continued to climb with few massive jumps in either direction, negative or positive.

b. The Australian Bureau of Statistics says wages climbed just 2.2 per cent ...

c. These data show that temperatures have climbed to more than $1.8^{\circ} \mathrm{F}$ $\left(1^{\circ} \mathrm{C}\right)$ above pre-industrial levels...

To explicate these uses, a third kind of [d]-mechanism is needed. It can be termed 'analogy of effect' (cf. Goddard 2015). Roughly and loosely, the idea is that 'something happens to this number [m] like something happens to someone when this someone is climbing [d] something'that is, it moves steadily upwards. A similar approach can be used for the place-based phraseological cluster in which a road, trail, railway line or the like is said to climb through the mountains, etc.

\section{Climbing, a tree (ladder, wall)}

It is time now to address the semantically basic meaning of climb, that is, the meaning found in its 'activity-in-progress' frame, as in sentences such as the following.

(5) a. She was climbing a tree in the backyard.

b. He was climbing a ladder when he fell.

A note is in order here about English grammar. English puts the thing/ place being climbed in the direct object/accusative role, but quite a number of languages do otherwise, expressing it in a locational phrase marked by a locative (or other oblique) adposition or case: for example, Yankunytjatjara punu-ngka kalpanyi 'climbing (on) a tree'. From an 'objective' point of view, this would seem very natural, insofar as a tree 
(ladder, wall, etc.) is not particularly affected by the climbing. After all, when one climbs a tree or ladder, one can hardly be said to be 'doing something to it'. 6

An explication for English climbing (a tree, ladder) is given in [D] below. Here are brief comments on each of its four main sections. The Lexicosyntactic Frame is the same as used for other verbs of locomotion (Goddard, Wierzbicka and Wong 2016). ${ }^{7}$ In the Prototypical Scenario, note the prior intention or a preparatory thought ('a short time before, this someone thought about it like this: ...'). ${ }^{8}$ This makes sense because climbing is not a routine everyday activity like walking: it requires an effort, and it requires something like a 'commitment'. When someone sets out to climb something, they are aware of the possibility of physical harm to their bodies, associated with the possibility of falling. There is more discussion of the prototypical scenario after the explication. I would only add at this point that the actor's cognitive focus on the thing being climbed may help explain why it appears (in English) in the direct object position.

The How it Happens (Manner) section includes an iterative structurethat is, brief repeated episodes involving coordinated moving and touching with the hands and parts of the legs-followed by a whole-body action which brings about an incremental effect - that is, 'this someone's body is above the place where it was before'. If this iterated process carries on for long enough, the Potential Outcome is that the person 'can be at the top $[\mathrm{m}]$ of this big thing as they wanted'.

Note that explication [D] uses the English-specific they (singular) as a 'portmanteau of convenience' for 'this someone'.

6 Of the 36 languages surveyed in the ValPal project on valency frames (valpal.info/meanings/ climb), about 10 appear either to follow or to prefer the oblique pattern with climb: Ainu, Eastern Armenian, Evenki, Korean, Mandinka, Yucatek Maya, Zenzontepec Chatino, Sri Lanka Malay, Ojibwe and Japanese (Hartmann, Haspelmath and Taylor 2013).

$7 \quad$ Climb can be used intransitively, e.g. He was climbing, and, in this frame, it looks parallel on the surface to the verb crawl, whose Manner also involves coordinated movements and contact by hands and legs. There are also other intransitive motion verbs, like swim and $f y$, which have special Manners adapted to the challenges presented by bodily motion in places of different kinds. I experimented with using 'intransitive climb' as the basic frame, but my eventual conclusion was that it is a case of omitted object construction, with the 'expected' object being place-like.

8 A similar component appears in the explications for transitive physical activity verbs such as cut, chop and grind (Goddard and Wierzbicka 2016). 


\section{[D] Someone is climbing ${ }_{1}$ something $Y$ (e.g. a tree, a ladder, a wall)}

someone is doing something for some time in a place

LEXICOSYNTACTIC

because of this, they are moving in this place during this

FRAME

time as they want

often when someone does this, it is like this:

PROTOTYPICAL

there is something big (of one kind) in the place where SCENARIO there this someone is

a short time before they thought about it like this:

'I am far from the top [m] of this big thing now, I want to be at the top [m] of this big thing after some time

I can't be there if I don't do some things with my body for some time

I know that it is like this:

when I am doing it, I will be far above the ground $[\mathrm{m}]$ for some time

because of this, it can be bad for me if something happens not as I want something bad can happen to my body'

when someone does this, their hands [m] touch this big thing in many places, parts of their legs [m] touch this big thing in many places

it often happens like this:

HOW IT HAPPENS

(MANNER) INCL. INCREMENTAL EFFECT

for a short time they do something with one hand [m] because of this, this hand [m] touches this something somewhere above where it touched it before after this, they do something with one leg [m] because of this, part of this leg $[\mathrm{m}]$ touches this something somewhere above where it touched it before after this, they do something with the body because of this, after this, the body is above the place where it was before

it happens like this many times 
if this someone does this for some time, after this they can

POTENTIAL be not in the place where they were before

they can be at the top [m] of this big thing as they wanted

The most notable aspects of explication [D] are in its prototypical scenario section, ${ }^{9}$ so I will comment further on this. Most of the proposed prototypical scenario relates to the prior intention of the actor, including their awareness that to achieve the goal 'to be at the top of this big thing after some time' necessarily involves 'doing some things with my body', and being aware at the same time that there is an element of risk involved in being 'far above the ground'; that is, 'it can be bad for me if something happens not as I want, something bad can happen to my body'. This kind of mindset, I would argue, is intuitively plausible for climbing, such as in 'climbing a tree'.

The actor's initial construal that 'I am far from the top of this big thing' helps explain why expressions like climb the ladder can sound appropriate even about a small stepladder, provided that the actor is a toddler or young child. It is the subjective point of view that matters, not whether the distance to the top is or isn't 'far' from the point of view of a disinterested observer. Notice also that the prospect of bodily harm does not hinge entirely on the climber making a mistake, such as slipping from a handhold or foothold. It could come about from other (unspecified) mishaps, such as a weaker-than-expected branch giving way or something falling from above.

These various elements of the prototypical actor's mental state (the construal of a far distance to be covered and implied need for caution and concentration) help explain extended uses of climb in expressions like climb the stairs. Climb the stairs is a high-frequency expression, but it does not mean the same, nor is it used in the same range of contexts, as alternatives such as take the stairs or go upstairs. The expression climb the stairs implies effort, and for a physically fit person, this might imply (say) three or four flights of stairs. On the other hand, for a person who is weak from illness, injury or frailty, even going up a single flight of stairs can be described as climbing the stairs.

9 The Manner section may seem rather detailed in its 'motor pattern', but it is roughly comparable to the Manner sections of the explications for crawl and run (Goddard and Wierzbicka 2016; Goddard, Wierzbicka and Wong 2016). 
The same applies (even more so) to climb down the stairs. Given that going downwards is usually less physically demanding than ascending, it makes sense that the range of use of climb down the stairs is even more restricted. Climbing down the stairs only feels appropriate when speaking of someone who is weak or unsteady on their feet, or, alternatively, in situations where the stairs are perceived to be steep and dangerous.

The physical demands of climbing something, together with the need for caution, help explain why the default assumption is that climbing is normally done slowly and steadily, and this implication carries over when 'climbing' is used as a [d] element in analogy of manner or analogy of effect components, such as we saw in section 4. (In Wordbanks, the most typical manner adverbs to collocate with climb are steadily, slowly, cautiously, laboriously and unsteadily.)

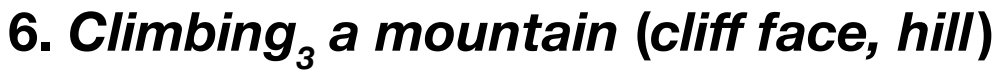

Object noun phrases such as mountain, cliff face and hill are not fully compatible with $\operatorname{climb}_{1}$ as explicated in [D] above: first, because mountains and the like are 'places (of one kind)', rather than things (in a place) (Bromhead 2018); and second, because the physical aspects and time frame of climbing a mountain, cliff face, etc. are significantly different-for example, it takes much longer and special equipment is often involved.

(6) a. Many people want to climb Mt Everest, Mt Cook, Mt Fuji, Mt Warning, etc.

b. Who has climbed the Dawn Wall [a famous cliff face]?

For these sentences, it is necessary to posit a third, polysemic meaning climb $_{3}$. It is explicated in [E] below. The main differences are, first, that in the prototypical scenario the nature of the place is described: 'this place is a big place (of one kind)'; second, that the preparatory thought is depicted as taking place 'some time before', rather than 'a short time before', as with $\operatorname{climb} b_{1}$ (this is connected with the fact that climbing a mountain, hill, cliff, etc. is a more substantial undertaking); and third, that in the How it Happens (Manner) section, the person is depicted as doing 'some things in this place for some time like someone does when this someone is climbing [d] something'. 


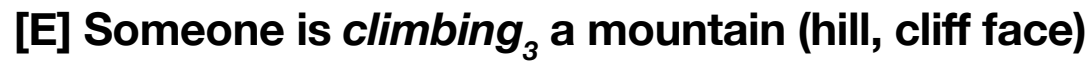

someone is doing something for some time in a place

LEXICOSYNTACTIC

because of this, they are moving in this place during this

FRAME

time as they want

often when someone does this in a place, it is like this:

PROTOTYPICAL

this place is a big place of one kind

SCENARIO

some time before, this someone thought like this about this place:

'I am far from the top [m] of this big place now

I want to be at the top [m] of this big place after some time

I can't be there if I don't do some things with my body for some time

I know that it is like this:

when I am doing it, it can be bad for me

if something happens not as I want

something bad can happen to my body

because of it'

when someone does this, it happens like this:

HOW IT HAPPENS

(MANNER)

this someone does some things in this place for some time like someone does when they are climbing [d] something

if this someone does this for some time, after this, they can

POTENTIAL be at the top [m] of this big place, as they wanted

OUTCOME

In connection with $\operatorname{climb}_{3}$, one should note the existence of a slew of specialised terms and phrases for mountain climbing and rock climbing.

(7) a. mountain climber, climbers

b. climbing gear, climbing ropes, climbing routes, the summit climb

c. mountain climbing, rock climbing, sports climbing, free climbing, indoor climbing

There are collocational facts to be mined as well; for example, the possibility of these meanings appearing in coordinate constructions with words such as hiking, trekking and canoeing. 


\section{She climbed ${ }_{4}$ the fence (gate): A covert alternation with 'climb'}

First, a bit of additional background is necessary. In the literature on syntactic alternations, a specialised 'crossing an obstacle' construction has been identified with intransitive English verbs of motion such as swim or jump, which imply significant bodily effort. In this specialised construction, the verb appears in a transitive frame; however, as shown in (8) and (9), the transitive versions are roughly synonymous with intransitive sentences that include a prepositional phrase with across or over.

(8) He swam the river.

$\approx$ He swam across the river.

(9) She jumped the puddle.

$\approx$ She jumped over the puddle.

To the best of my knowledge, the 'crossing an obstacle' construction has not previously been recognised in the literature on the verb climb, because, English $\operatorname{clim} b$ being already transitive in appearance, the construction does not show itself via a change in surface argument structure. But consider:

(10) a. He climbed the ladder/mountain.

* He climbed over the ladder/mountain.

b. He climbed the fence (gate, garden wall).

$\approx$ He climbed over the fence (gate, garden wall).

c. ${ }^{*}$ He climbed upldown the fence (gate, garden wall).

The examples in (10a) show that with canonical objects such as ladder and mountain, sentences with climb are not near-synonyms of agnate sentences with prepositional phrases using over - that is, to climb a ladder and to climb over a ladder mean something quite different to one another. However, when the object is something like a fence, a gate or a (garden) wall - a barrier that can be crossed - the equation goes through, as shown by the examples in (10b): to climb a fence and to climb over a fence do mean much the same. 
Another indication that we are dealing here with a separate construction is that, as shown by the examples in (10c), adverbs like $u p$ and down cannot normally be added to 'crossing an obstacle' sentences with climb. It may also be noted that 'crossing an obstacle' sentences with climb (like comparable sentences with swim and jump) usually sound much better in the simple past than in the progressive.

For these reasons, it is necessary to recognise an additional constructional schema, with a distinctive motivation ('I want to be on the other side of this thing here'), as shown in $[\mathrm{F}]$.

\section{[F] He climbed ${ }_{4}$ the fence (gate)}

he did something in a place at this time

it happened like this:

a short time before, he thought like this about something in this place (a fence, gate):

'I want to be on the other side of this thing here' because of this, for a short time he did something in this place like someone does when this someone is climbing [d] something

because of this, after this, he was not in the place where he was before

he was on the other side of this thing as he wanted
LEXICOSYNTACTIC FRAME

HOW IT HAPPENED

(MANNER)

This concludes the present study of the lexicogrammar of English climb.

\section{Concluding remarks}

Given the complexity of the explications and wide range of uses I have endeavoured to cover in this short study, many improvements are no doubt possible. There is certainly scope for more detailed corpusanalytical work. It would also be extremely valuable to bring comparisons with other languages into the picture. There are sure to be many subtle but significant differences between 'climb words' in different languages. Pinpointing these differences would help firm up the optimal phrasing of various components. It is entirely possible that some cross-linguistic 
differences will turn out to be related to different geographic environments and lifestyles of the speakers concerned. One would also expect that cross-linguistic differences in the basic meanings will have downstream effects so far as extended meanings are concerned.

It should be emphasised that much of the present study has been concerned not with the semantically basic meaning of English climb, but with how this core or basic meaning can be extended and enriched by being embedded into different constructional frames. In English, the favourite mechanisms for doing this are syntactic in character, principally involving alternative prepositional phrases. In other languages, comparable meanings may be expressed by devices such as derivational morphology, verb compounding or serial verb constructions.

To conclude on a general note, it should be clear that the verb climb provides a perfect example of lexis, morphology, phraseology and syntax all working together to express varied and subtle meanings.

\section{References}

Bromhead, Helen (2018). Landscape and Culture - Cross-linguistic Perspectives. Amsterdam: John Benjamins.

Chen, Sherry Yong and E. Matthew Husband (2019). Event (de)composition. In Chris Cummins and Napoleon Katsos (eds), Oxford Handbook of Experimental Semantics and Pragmatics. Oxford: Oxford University Press, 62-82. doi.org/10.1093/oxfordhb/9780198791768.013.10.

Comrie, Bernard (1993). Aspect. Cambridge, UK: Cambridge University Press.

Dowty, David (2000). 'The garden swarms with bees' and the fallacy of 'argument alternation'. In Yael Ravin and Claudia Leacock (eds), Polysemy: Theoretical and Computational Approaches. Oxford: Oxford University Press, 111-28.

Fillmore, Charles J. (1982). Towards a descriptive framework for spatial deixis. In R. J. Jarvell and W. Klein (eds), Speech, Place and Action: Studies in Deixis and Related Topics. London: Wiley, 31-59.

Geuder, Wilhelm and Matthias Weisgerber (2006). Manner and causation in movement verbs. In Christian Ebert and Cornelia Endriss (eds), Proceedings of 'Sinn \& Bedeutung 10' (vol. 1). Berlin, ZAS Papers in Linguistics 44, 1. Available online via: www.leibniz-zas.de/en/research/publications/details/ publications/4234-proceedings-of-the-sinn-und-bedeutu/. 
Goddard, Cliff (2011). Semantic Analysis: A Practical Introduction (2nd edn). Oxford: Oxford University Press.

Goddard, Cliff (2012). Semantic primes, semantic molecules, semantic templates: Key concepts in the NSM approach to lexical typology. Linguistics 50 (3): 711-43. doi.org/10.1515/ling-2012-0022.

Goddard, Cliff (2015). Verb classes and valency alternations (NSM approach), with special reference to English physical activity verbs. In Andrej Malchukov and Bernard Comrie (eds), Valency Classes in the World's Languages. Berlin: Mouton de Gruyter, 1649-80. doi.org/10.1515/9783110429343-020.

Goddard, Cliff (2018). Ten Lectures on Natural Semantic Metalanguage: Exploring Language, Thought and Culture Using Simple, Translatable Words. Leiden: Brill.

Goddard, Cliff and Anna Wierzbicka (2014). Words and Meanings: Lexical Semantics Across Domains, Languages and Cultures. Oxford: Oxford University Press. doi.org/10.1093/acprof:oso/9780199668434.001.0001.

Goddard, Cliff and Anna Wierzbicka (2016). Explicating the English lexicon of 'doing and happening'. Functions of Language 23 (2): 214-56. doi.org/ 10.1075/fol.23.2.03god.

Goddard, Cliff, Anna Wierzbicka and Jock Wong (2016). 'Walking' and 'running' in English and German: The conceptual semantics of verbs of human locomotion. Review of Cognitive Linguistics 14 (2): 303-36. doi.org/ 10.1075/rcl.14.2.03god.

Hartmann, Iren, Martin Haspelmath and Bradley Taylor (eds) (2013). Valency Patterns Leipzig. Leipzig: Max Planck Institute for Evolutionary Anthropology.

Jackendoff, Ray (1983). Semantics and Cognition. Cambridge, MA: MIT Press.

Jackendoff, Ray (1985). Multiple subcategorization and the $\theta$-criterion: The case of climb. Natural Language \& Linguistic Theory, 3 (3): 271-95. doi.org/10.1007/ bf00154264.

Jackendoff, Ray (1990). Semantic Structures. Cambridge, MA: MIT Press.

Levin, Beth and Malka Rappaport Hovav (2013). Lexicalized meaning and Manner/Result complementarity. In Boban Arsenijević, Berit Gehrke and Rafael Marín (eds), Studies in the Composition and Decomposition of Event Predicates. Springer, 49-70. doi.org/10.1007/978-94-007-5983-1_3. 
Rappaport Hovav, Malka and Beth Levin (2010). Reflections on Manner/Result Complementarity. In Malka Rappaport Hovav, Edit Doran and Ivy Sichel (eds), Lexical Semantics, Syntax, and Event Structure. Oxford: Oxford University Press, 21-38. doi.org/10.1093/acprof:oso/9780199544325.003.0002.

Sibly, Anne (2010). Harry slapped Hugo, Tracey smacked Ritchie: The semantics of slap and smack. Australian Journal of Linguistics 30 (3): 323-48. doi.org/ 10.1080/07268602.2010.498804.

Wierzbicka, Anna (1982). Why can you have a drink when you can't *have an eat? Language 58 (4): 753-99. doi.org/10.2307/413956.

Wierzbicka, Anna (1988). The Semantics of Grammar. Amsterdam: John Benjamins.

Wierzbicka, Anna (1996). Semantics: Primes and Universals. Oxford: Oxford University Press.

Ye, Zhengdao (2010). Eating and drinking in Mandarin and Shanghainese: A lexical-conceptual analysis. In Wayne Christensen, Elizabeth Schier and John Sutton (eds), ASCS09: Proceedings of the 9th Conference of the Australasian Society for Cognitive Science. Sydney: Macquarie Centre for Cognitive Science, $375-83$. 
This text is taken from Meaning, Life and Culture: In conversation with Anna Wierzbicka, edited by Helen Bromhead and Zhengdao Ye, published 2020 by ANU Press, The Australian National University,

Canberra, Australia.

doi.org/10.22459/MLC.2020.01 